\section{Taller estero Marga Marga \\ Viña del Mar, Chile}

El cauce del estero Marga Marga en la ciudad de Viña del Mar, abandonado y utilizado muchas veces con fines poco enriquecedores para el desarrollo urbano, es el foco para la intervención de un taller que busca canalizar las variables presentes en la ciudad: desarrollos inmobiliarios, espacios públicos y relaciones espaciales en primeros pisos.
The riverbed of the Marga Marga canal in Viña del Mar, abandoned and often used for purposes offering little enrichment to urban development, is the focus for the intervention of a workshop that seeks to canalize the present variables in the city: real estate developments, public spaces and ground floor spatial relationships.

Enrique del Río Profesor, Pontificia Universidad Católica de Chile

Pilar García Subdirectora académica, Escuela de Arquitectura de la Pontificia Universidad Católica de Chile

José Rosas Decano, Facultad de Arquitectura, Diseño y Estudios Urbanos de la Pontificia Universidad Católica de Chile

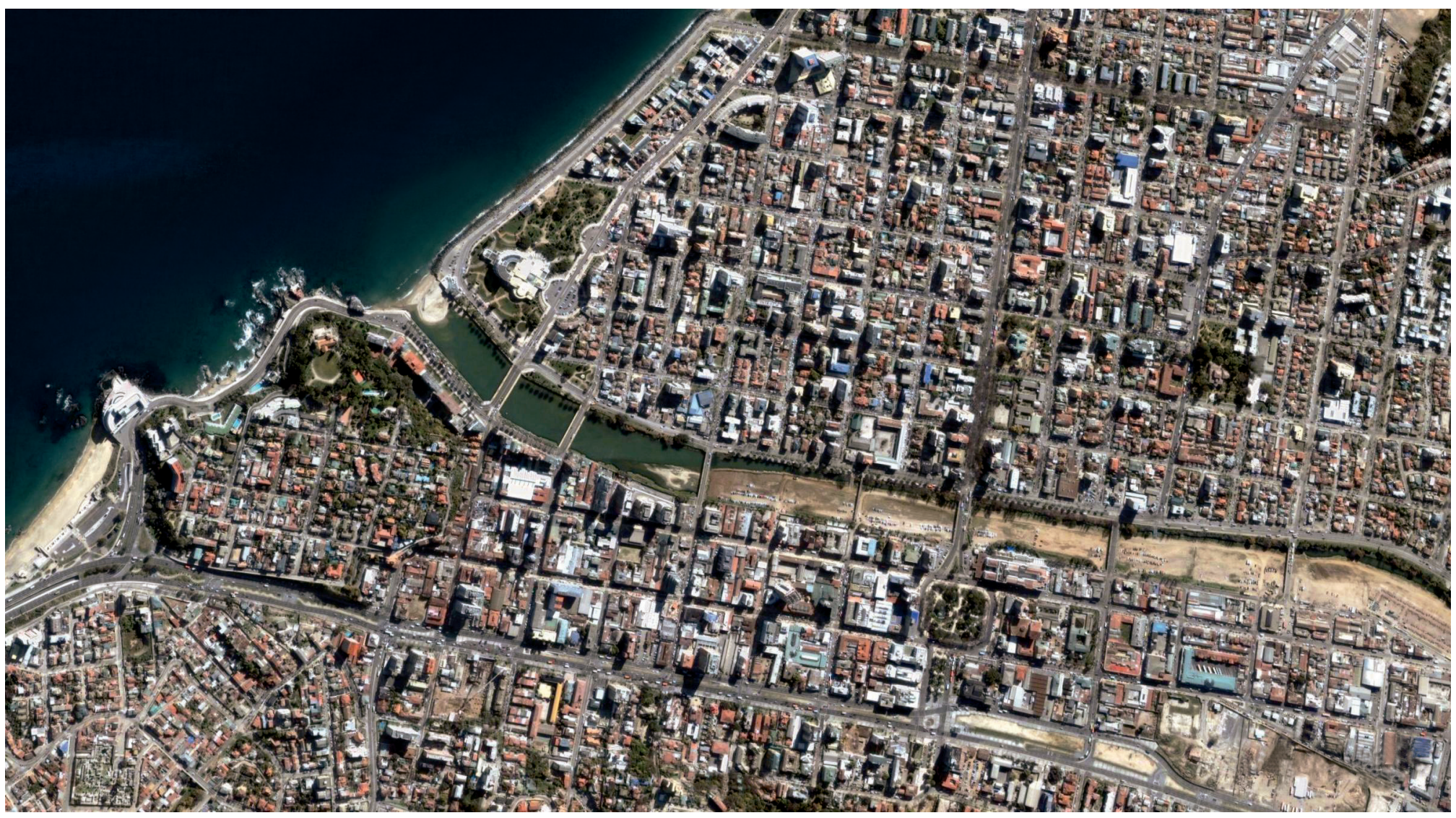

01 Estero Marga-Marga, Viña del Mar. Situación Actual. Fuente: Senvicio de imágenes del planeta Google Earthrm 


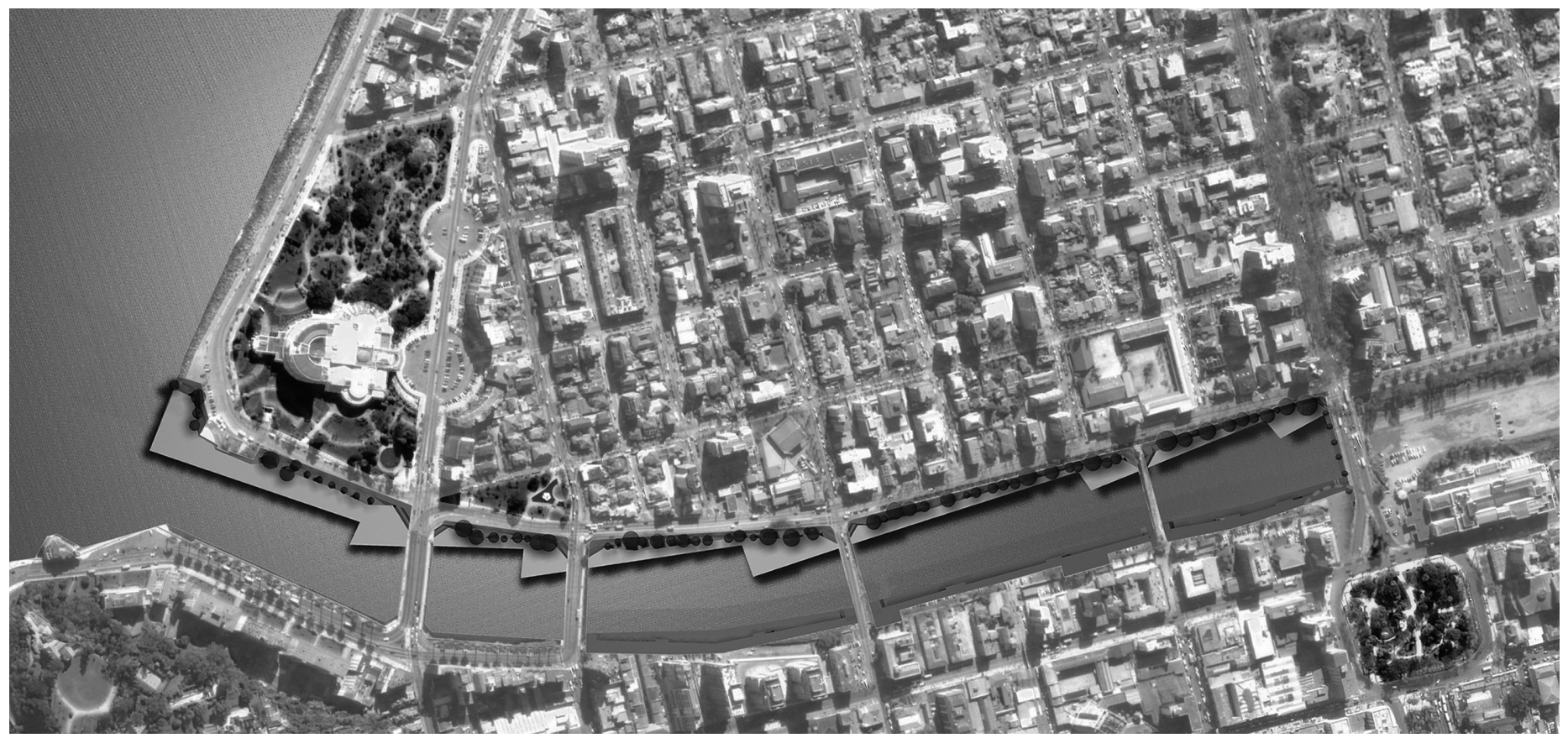

04 Proyecto de los alumnos Guillermo Rojas, Daniela Camousseigt y Marieta González

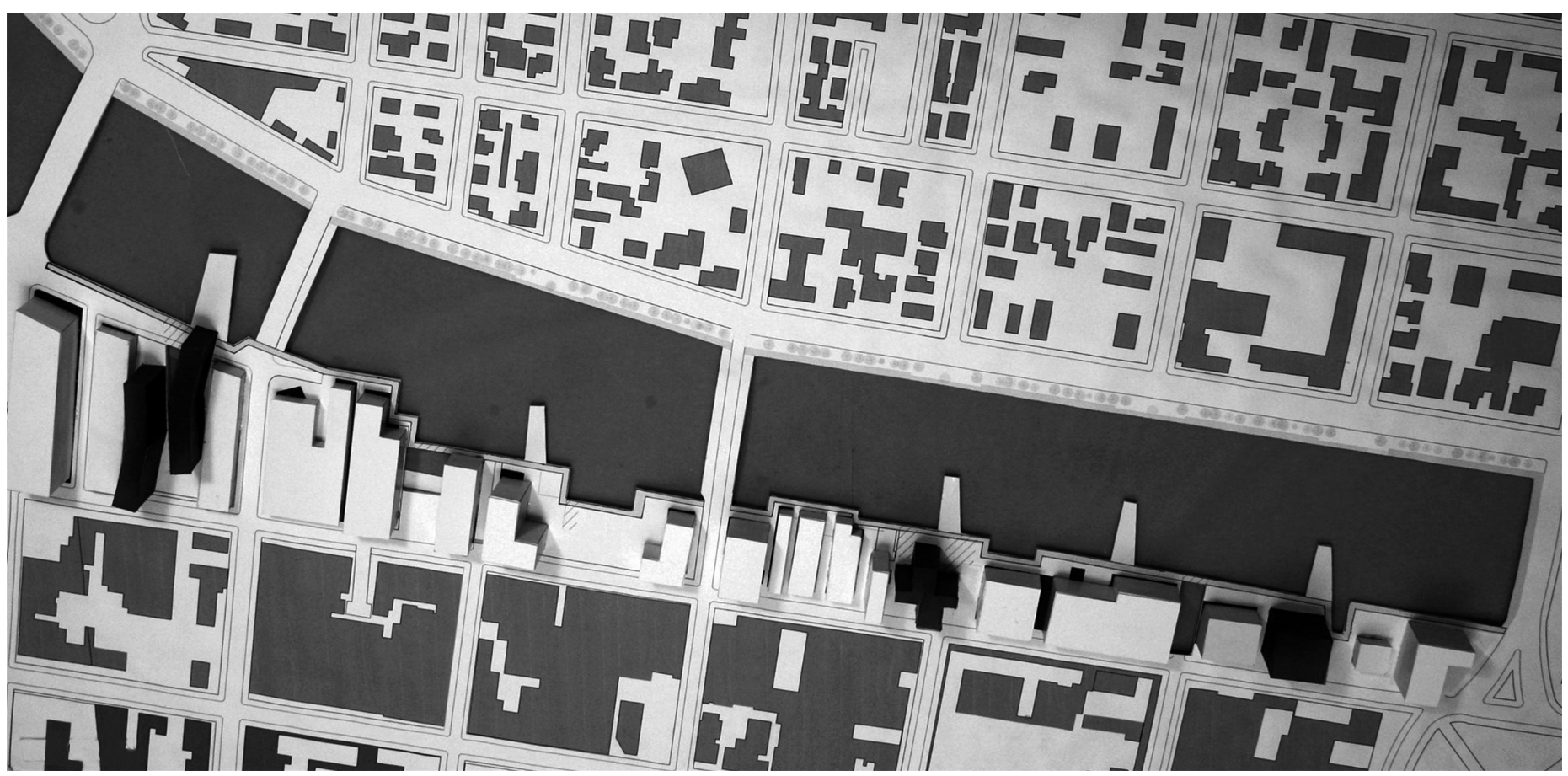

05 Proyecto de los alumnos Daniel Arellano, Ignacio Abé y Rodrigo Court 


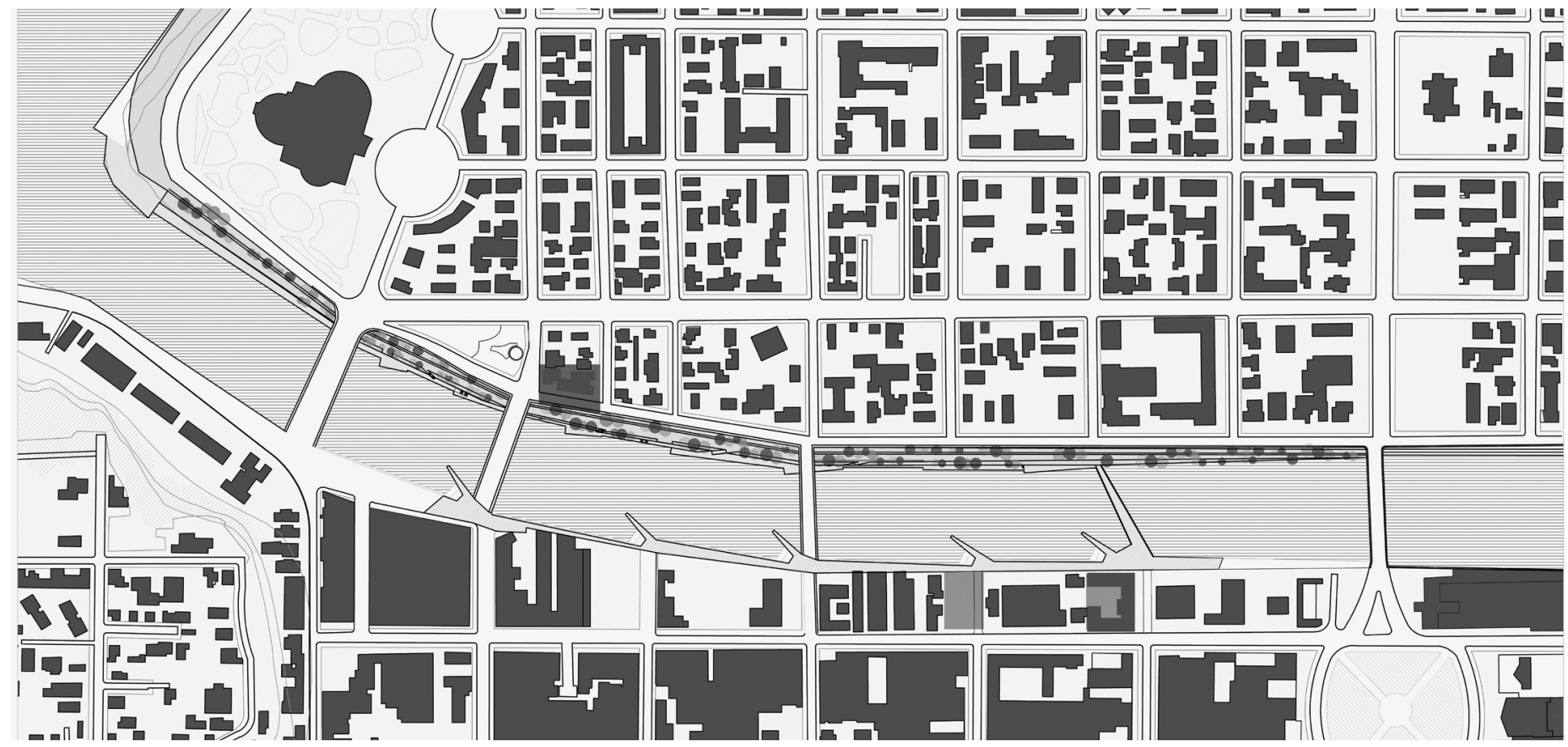

06 Proyecto de los alumnos José Lemaitre, Nicole Pumarino y Camila Medina

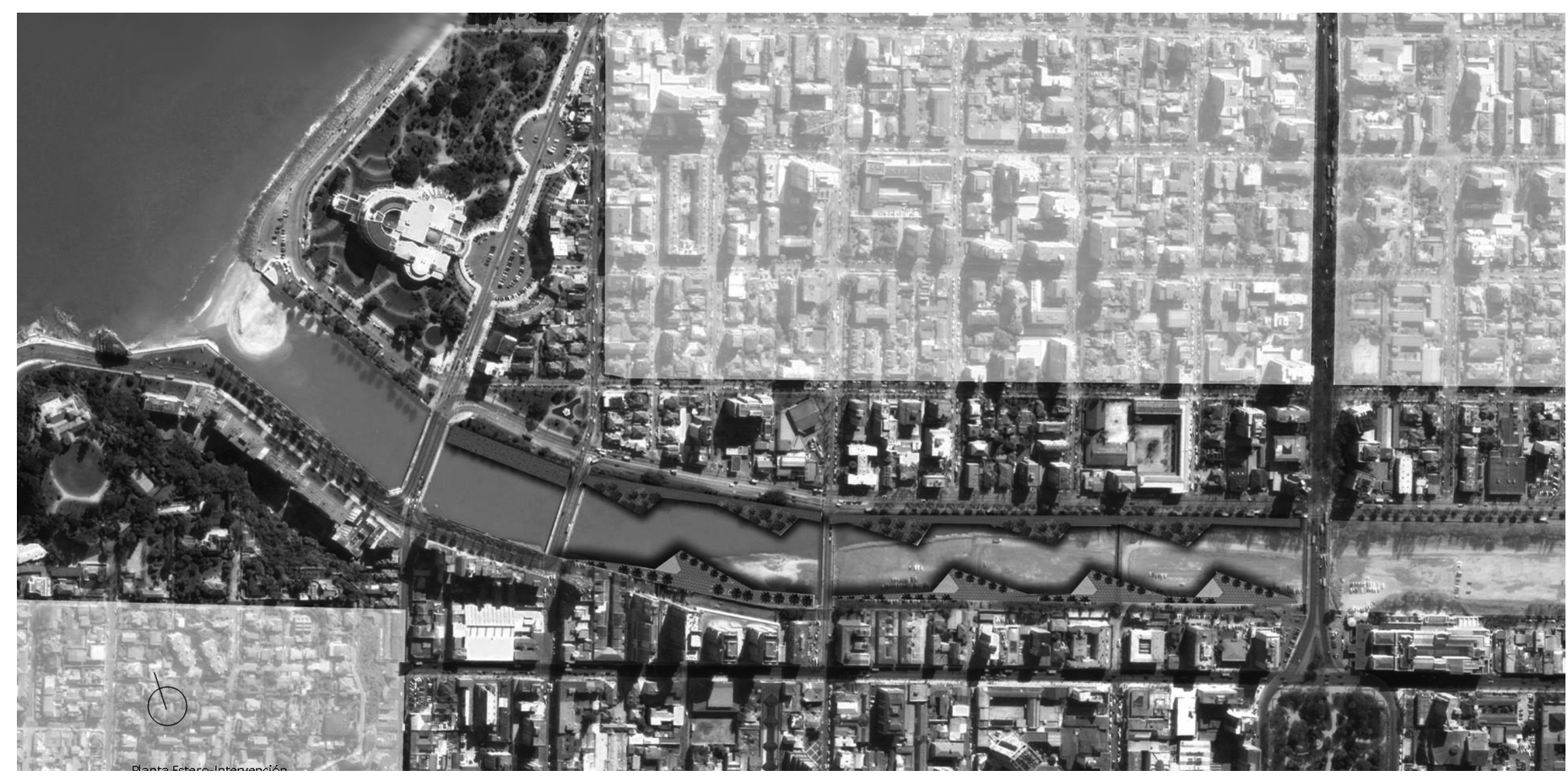

07 Proyecto de los alumnos Raúl Muñozy Matías Echavarría

TALLER ESTERO MARGA-MARGA

Profesores Pilar García, Enrique del Río, José Rosas

Instructores Martín Labbé, Mario Carreño, Alejandro Beals, Josefina del Río

Ubicación estero Marga-Marga, Viña del Mar, Chile Nombre curso Taller de Formación $\mathrm{V}$

Universidad Pontificia Universidad Católica de Chile Año proyecto segundo semestre 2008 